\title{
EdUCOMUNICAÇÃO E SAÚDE EM SINTONIA NO RÁDIO
}

\section{Educommunication and health tuned on the radio Educomunicación y salud en sintonía en la radio}

\author{
Darcilia Moyses ${ }^{1}$ \\ Flávia Mayer dos Santos Souza² \\ Gilda Soares Miranda ${ }^{3}$ \\ Maria Cristina Dadalto ${ }^{4}$
}

\begin{abstract}
RESUMO
Este trabalho relata a trajetória do projeto de extensão em rádio desenvolvido no Centro Universitário Vila Velha (UVV), nos anos de 2008 e 2009. De natureza interdisciplinar, o projeto volta-se para a produção de programas radiojornalísticos com temáticas do campo da saúde. A atividade, realizada na graduação em Jornalismo, caracteriza-se pela parceria com cursos da área da saúde, que contribuem desde a formulação das pautas até a análise dos produtos gerados. O desenvolvimento e o reconhecimento da importância desse projeto pela equipe docente e discente envolvida levaram ao incremento das atividades laboratoriais. Foi realizado, então, um acompanhamento crítico, tendo como base a teoria da educomunicação, com vistas a implementar ações pedagógicas reflexivas no curso de comunicação que possibilitem a formulação de uma práxis pedagógica laboratorial que compreenda o universo proposto.
\end{abstract}

Palavras-chave: extensão universitária; radiojornalismo; educomunicação; saúde; interdisciplinaridade.

\begin{abstract}
This text reports the history of the extension project in radio developed in the Centro Universitário Vila Velha (UVV), between 2008 and 2009. This interdisciplinary project produces radio journalistic programs with health themes. The activity was accomplished during the Journalism graduation, and it was characterized by partnership with health courses, which contributed to the creation of guidelines and the analysis of the generated products. The development and recognition of the importance of this project by the teaching staff and students involved in those activities led to an increase on the laboratory activities. Then, a critical monitoring was performed, based on the theory of educommunication, to implement reflective actions in the communication course enabling the formulation of pedagogical practice at the laboratory level to understand the proposed universe.
\end{abstract}

Keywords: university extension; radiojournalism; educommunication; health; interdisciplinary.

\footnotetext{
${ }^{1}$ Mestre em Estudos Literários, professora do curso de Comunicação Social do Centro Universitário Vila Velha, Rua Comissário José Dantas de Melo, Boa Vista, Vila Velha, ES, 29102-770, (27) 3421-2076, darcilia@uvv.br

${ }^{2}$ Mestre em Educação, professora do curso de Comunicação Social do Centro Universitário Vila Velha, flavia.mayer@yahoo.com.br

3 Mestre em Educação, professora do curso de Comunicação Social do Centro Universitário Vila Velha, gildasmiranda@yahoo.com.br

${ }^{4}$ Doutora em Ciências Sociais, professora do curso de Comunicação Social do Centro Universitário Vila Velha, dadalto@uvv.br
} 


\section{RESUMEN}

Relata la historia del proyecto de extensión de radio desarrollado en el Centro Universitário Vila Velha (UVV), en los años 2008 y 2009. Este proyecto interdisciplinario produce programas con temas radio periodístico el ámbito de la salud. La actividad, que se realizó en la graduación en Periodismo, se caracteriza por la asociación con cursos en materia de salud, que contribuyen con la formulación de las directrices y el análisis de los productos generados. El desarrollo y el reconocimiento de la importancia de este proyecto por el personal docente y los estudiantes participantes aumentaran las actividades dirigidas de laboratorio. Se realizó entonces un seguimiento crítico, basado en la teoría de la educomunicación, para ejecutar acciones pedagógicas pensativas en el curso de la comunicación y permitan la formulación de una práctica pedagógica en el laboratorio para entender el universo propuesto.

Palabras clave: extensión universitária; radioperiodismo; educomunicación; salud; interdisciplinariedad.

\section{Introdução}

Como o campo do ensino pode ser pensado para que os futuros profissionais das áreas de comunicação social atuem de forma mais interativa, complexa e eficaz com relação ao campo da saúde? Na graduação em comunicação é possível estabelecer uma competência para atender às demandas sociais da comunicação pública de saúde? Essas são algumas das inquietações que têm motivado a aproximação dos campos da comunicação e da saúde. As ações e discussões críticas sobre a temática têm permeado, sobretudo, os cursos de pós-graduação, contudo, poucas são, pelo menos em termos de divulgação, aquelas promovidas na graduação.

O escasso debate no âmbito da graduação torna urgente a reflexão sobre o processo de formação dos profissionais de comunicação para atuarem com a comunicação pública de saúde. Nesse sentido, o desafio está no campo da interdisciplinaridade e da transversalidade, que caracterizam a complexidade que move a visão de mundo, o sistema simbólico, as estruturas e as tipificações dessas demandas. Daí, para a melhor aproximação dos campos da comunicação e da saúde, torna-se necessário agregar as discussões do campo da educação. Com a parceria da educomunicação é possível refletir e avaliar criticamente a ação dos profissionais de comunicação em temas da saúde.

Busca-se, assim, partir das ponderações de Xavier (2006, p. 44) de que
[...] a comunicação em saúde tem um lugar de fala muito preciso e alguns importantes instrumentos, pelos quais é capaz de induzir muita reflexão, mas alcançar pouca repercussão e abrangência. [...] Os esforços no âmbito da comunicação em saúde permanecem, com poucas exceções, restritos aos seus próprios ambientes de produção: instituições governamentais, universidades, profissionais da saúde, tendo dificuldade de alcançar até mesmo os próprios serviços de saúde.

Para melhor refletir sobre essa necessidade de alargar os limites da cobertura dada pelos meios de comunicação sobre o tema da saúde, evidenciada pelo autor, recorreu-se à concepção da educomunicação para a saúde. Nessa perspectiva, a teoria abre a possibilidade de compreender, de forma cada vez mais ampla, o papel da comunicação na formação e informação da sociedade, tendo a função, também, de propiciar acesso à cidadania, seja difundindo informações e orientações de caráter coletivo com relação ao desenvolvimento das áreas de saúde, seja contribuindo para difundir junto à opinião pública a saúde como um direito subjetivo.

O fortalecimento do cidadão constitui, então, um dos principais objetivos do encontro dos campos da educação e da comunicação. A partir desse referencial, os meios de comunicação 
deslocam-se de uma fala para alguém e passam para a perspectiva de uma fala com, de modo que a relação entre receptor e mídia passa a ser menos assimétrica. O receptor adentra, também, como produtor, como alguém que, ao mesmo que tempo em que se informa com a mídia, também forja espaços nos meios de comunicação.

Assim, a Ciência da Comunicação volta-se para a Educação na busca de um espaço de relações pessoais no qual possa trabalhar com os aspectos cognitivos, críticos e comportamentais do público e onde prevaleça, por sobre os interesses comerciais e econômicos, uma postura formativa e libertadora (COSTA, 2008, p. 2).

$\mathrm{O}$ artigo volta-se, nesse contexto, para a reflexão sobre a aproximação das áreas da comunicação, educação e saúde, por meio de experiência desenvolvida no âmbito do projeto de extensão em rádio desenvolvido no curso de Jornalismo do Centro Universitário Vila Velha.

Iniciada em 2008 e ainda em curso, a proposta parte do pressuposto de que é indispensável que haja um maior conhecimento das práticas de comunicação e saúde por ambas as áreas. Caso se considere acompanhar as ações e estratégias de comunicação focadas na saúde em nosso país, desenvolvidas tanto por ONGs quanto pelos Governos ou por empresas privadas, evidenciam-se alguns equívocos $e$ distorções que penalizam, sobretudo, o usuário da informação, seja ele um leitor de jornais $e$ revistas, um radiouvinte, um telespectador ou um internauta. Concorrem para definir este cenário fatores intrínsecos ao processo de comunicação, envolvendo tanto quem fala (fonte/profissionais da área de saúde) como quem produz a informação (jornalista/publicitário) como o receptor (público-alvo da informação). Nesse sentido, Bueno (2008, p. 671) pondera que

Para se chegar, portanto, a uma terapêutica adequada, capaz de debelar a doença (a ineficácia do processo de comunicação em saúde), será necessário um diagnóstico abrangente que contemple não apenas o paciente (a mídia brasileira especificamente), mas o contexto em que ele se insere. Em princípio, essa abordagem não tem nada de inovadora, ainda que, no campo da saúde, a especialização conduza a atenção para o detalhe em detrimento do todo.

Perante o desafio apresentado, professores e estudantes dos cursos de Comunicação Social (Jornalismo e Publicidade e Propaganda), junto com professores dos cursos de Fisioterapia, Enfermagem, Nutrição, Fonoaudiologia, Medicina e Psicologia do Centro Universitário Vila Velha, iniciaram uma discussão sobre a realização de atividades jornalísticas especializadas em comunicação e saúde. Desse modo, o presente projeto busca promover uma práxis interdisciplinar e transversal, fundamentada na educomunicação.

A produção em rádio voltada para educomunicação e saúde

A experiência de produção em rádio voltada para educomunicação e saúde foi iniciada em outubro de 2008. Nesse período, professores e estudantes dos cursos de Comunicação Social (Jornalismo e Publicidade e Propaganda), bem como professores de seis diferentes cursos da área da saúde começaram a esboçar o processo para a produção de programas de radiojornalismo sobre temáticas da saúde. Dessa maneira, o percurso foi trilhado conjuntamente, 
definições e estratégias decididas na coletividade, considerando que a reflexão crítica acerca do processo comunicativo configura a base de um projeto de educomunicação.

A partir do Manual de Educomunicação desenvolvido pelo Ministério da Educação (2006) foram definidas as etapas para a realização do projeto, que envolveram: 1) reuniões de discussão da proposta, com os professores dos cursos envolvidos no projeto e estagiários de Jornalismo; 2) pesquisa de pautas de interesse de debate com estudantes universitários públicoalvo do programa; 3) produção de programas; 4) apresentação dos materiais; 5) avaliação, isto é, análise junto com os professores envolvidos, para reflexão do trabalho em desenvolvimento.

O processo de produção considerou, também, o perfil de público a ser atingido pelos programas. O projeto contou com a parceria da Rádio Cidade FM, que tem como público o jovem universitário. Desse modo, os temas a serem abordados, a linguagem e todo o passo a passo inerente à produção para rádio foram planejados tendo como foco esse perfil de público.

Em 2008, na primeira reunião de definição de pautas, foi sugerida, por um professor do campo da saúde, a discussão do tema anencefalia, bem como indicados os docentes que poderiam ser entrevistados sobre o assunto. Foram produzidos, assim, dois programetes sobre essa questão: um explicativo sobre o tema e outro específico sobre aborto de anencéfalo.

$\mathrm{Na}$ sequência, os programetes foram avaliados pelo corpo discente e docente das áreas de comunicação e de saúde. Os alunos de Jornalismo revelaram que, nesse primeiro momento, encontraram algumas dificuldades, por conta do desconhecimento de assuntos que surgiram no decorrer da entrevista. Tal aspecto apontou a necessidade de um estudo um pouco mais aprofundado sobre o tema antes da realização da entrevista e, para isso, os professores da área da saúde indicaram periódicos e sites que pudessem servir de base para os alunos de Jornalismo.
Nessa reunião de análise da produção, os professores da área de saúde deixaram claro que se surpreenderam com a qualidade dos produtos e evidenciaram como o espaço do rádio pode ter, de fato, um grande potencial para informar temas dessa natureza.

Na oportunidade, ponderou-se que, na perspectiva da educomunicação, os processos devem incitar maior participação do receptor. A partir de então, foi feito o levantamento com o público-alvo da rádio - constituído por jovens universitários - dos temas da área da saúde que lhes interessavam. Buscou-se, assim, uma aproximação com o público, mostrando o caráter da comunicação como uma via de mão dupla. Nessa perspectiva, a relação com a mídia, caracterizada por uma grande assimetria, é reconfigurada e o receptor tem condições de experimentar uma outra forma de comunicação, ou seja: se não há brechas que permitam a participação em grandes meios, há condições de forjá-las.

O lugar do receptor, como produtor, passa a ser destacado e, como partícipe desse processo, ele ocupa a posição de alguém que negocia os sentidos e, assim, significa e atribui outros possíveis sentidos para o produto veiculado na mídia (MARTIN-BARBERO, 2003). É justamente nesse ponto que a educação pode fortalecer o lugar do receptor, de modo que ele se posicione ativamente em relação ao produto midiático.

Nos três meses de projeto foram produzidos treze programas de radiojornalismo sobre temáticas variadas - anencefalia, aborto de anencéfalo, alteração postural, gagueira, hipertensão, ortopedia, serviços da clínica de fisioterapia para a comunidade, surdez, preservativo feminino, serviços do hospital veterinário para a comunidade, cuidados com a voz e dois sobre eventos realizados pelos cursos envolvidos no projeto (Jornada de Nutrição e Seminário de Traumatologia).

A atividade de educomunicação em saúde revelou que a experiência de aproximação do rádio com o público ainda precisava ser mais 
trabalhada. O levantamento foi a única maneira possível, num primeiro momento, de colher, com o público, informações sobre os assuntos da saúde que gostariam de conhecer mais. Desse modo, verificou-se a necessidade de criação de um canal - e-mail, por exemplo - para que o público possa manifestar os assuntos de seu interesse e participar ativamente da construção da programação.

De qualquer modo, as reuniões com o corpo docente e discente tornaram-se, assim, um fórum rico de debates que retroalimentavam o processo de produção. E, para dar mais agilidade às discussões, foi sugerido que os programas fossem enviados por e-mail aos membros desse grupo, para o acompanhamento do desenrolar do projeto.

Uma vez que o projeto havia proporcionado uma experiência de aprendizado para o corpo docente e discente e, também, aos ouvintes da rádio - que passaram a ter acesso a informações da área de saúde -, foi proposta a continuidade do programa em 2009. Desse modo, em março o projeto foi retomado e a equipe de extensão voltou às atividades.

Para que a produção educomunicativa fosse experimentada por um maior grupo de alunos de Jornalismo, foi estabelecido um rodízio entre os bolsistas e voluntários. De imediato, percebeu-se o interesse e o comprometimento dos alunos com o projeto, haja vista a extensa produção do primeiro semestre e a busca por temas relevantes - temas de destaque no momento, ligados às pesquisas de docentes $e$ discentes da área da saúde, dentre outros.

Entre março e junho de 2009 foram produzidos e veiculados quatorze programas abordando as seguintes temáticas: educação alimentar; estética e saúde; segurança hospitalar; aids; saúde vocal; transtornos mentais; hipertensão arterial; luta antimanicomial; tensão pré-menstrual; o amaranto na alimentação; a importância da amamentação; o poder das vitaminas; doenças da pele e lombalgia.
Os relatos dos alunos de Jornalismo bolsistas e voluntários da extensão em rádio -, o engajamento de toda a equipe na produção e o retorno dos professores e alunos da área da saúde levou à continuidade do projeto de educomunicação em saúde no segundo semestre de 2009. Os alunos de Jornalismo destacam, especialmente, que este é um espaço de aprendizagem importante, haja vista a necessidade de aprofundamento sobre as temáticas abordadas nos programas. O contato com as fontes de informação, profissionais da saúde parceiros no projeto, para a discussão prévia sobre a temática a ser abordada no programa, e a realização de uma pré-entrevista possibilitam uma investigação mais aprofundada das temáticas e, consequentemente, maior satisfação na produção radiofônica, além de um compromisso maior com o público ouvinte da programação da Rádio Cidade FM.

É justamente nesse ponto que a educação pode fortalecer o lugar do receptor, de modo que ele se posicione ativamente em relação ao produto midiático. Nessa direção, é fundamental que a educação para os meios de comunicação entre em espaços como a escola. Assim, à medida que os receptores (aqui compreendidos como corpo docente, discente e receptores da informação) se fortalecem - ainda que a relação com a mídia seja desigual -, terão mais oportunidades para compreender e questionar o que é veiculado.

Esses primeiros passos podem contribuir para o cenário vislumbrado por Pereira Júnior (UNESCO/UMESP/FAI, 2001, p. 435), para que:

[...] os meios de comunicação levassem ao cidadão informações sobre ações concretas que demonstrassem as diversas práticas de promover saúde e, acima de tudo, que favorecessem a efetiva participação de cada um na gestão de seus problemas de saúde. Por meio da conscientização, esperamos que a comu- 
nidade possa assumir, de forma cada vez mais lúcida e autônoma, seu papel de protagonista e agente social.

Essa práxis poderá, portanto, provocar mudanças para profissionais de comunicação $e$ saúde. Isso porque as informações especializadas na área da saúde não são facilmente acessíveis aos não iniciados (mesmo profissionais de uma especialidade têm dificuldade de acompanhar os avanços em outras especialidades médicas). Dessa forma, ao se defrontar com um profissional da saúde, o comunicador, normalmente, tem dificuldade de compreendê-lo, pois desconhece conceitos básicos e não está acostumado com seu discurso. Há na cultura do especialista uma disposição em não se comunicar com os leigos e esta disposição está manifesta no seu discurso, que é a expressão de uma autoridade. Contudo, não há comunicação se os interlocutores não comungam das mesmas experiências, linguagens ou se, pelo menos, não se esforçam para se fazer entender. Compreender e refletir criticamente sobre esse processo é fundamental para jornalistas e profissionais da área de saúde. Iniciar essa ação-reflexão no ensino superior é possibilitar uma mudança no olhar dos futuros profissionais.

\section{Considerações finais}

Durante os três meses de realização do projeto em 2008 e a experiência entre março e julho de 2009, foram produzidos vinte e sete programas de rádio, com duração de dois minutos cada, na perspectiva da educomunicação em saúde.

A análise desses produtos revelou para os docentes de Comunicação e dos cursos da Saúde e discentes de Jornalismo - a importância da aproximação dos campos, do aprofundamento do estudo e de experimentações maiores nesse âmbito.

Assim, a reunião dos diferentes olhares - da Comunicação e da Saúde - possibilitou grandes trocas: no planejamento da produção de programas de rádio sobre temáticas da saúde; na definição das fontes que dariam o suporte para a construção dos programas de rádio, bem como livros, revistas, sites e pesquisas que poderiam configurar base para as entrevistas; na análise crítica da cobertura de saúde pela mídia produzida pelo corpo discente do curso de Jornalismo, nas atividades de radiojornalismo; na avaliação, com base na teoria da educomunicação, da prática pedagógica em curso para o desenvolvimento das atividades de Comunicação e Saúde.

A trajetória proporcionou uma experiência enriquecedora para docentes e discentes, especialmente nas fases de definição de pautas e análise da produção. Os critérios utilizados para produção e análise-reflexão da práxis laboratorial eram exaustivamente debatidos com os professores das áreas de saúde, que contavam com uma seleção de artigos para leitura e produção das pautas. Por ser prática laboratorial, envolvendo professores de áreas interdisciplinares, possibilitou, especialmente aos estudantes de Jornalismo, o conhecimento de diferentes linguagens e códigos da área da saúde, até então não contemplados no ensino.

O percurso definido privilegiou, assim, tanto o processo quanto o produto. Dessa maneira, a experiência de gestão do processo comunicativo e, também, a produção desenvolvida, já que foram acompanhadas de análise e, consequentemente, de aprendizagem, contribuíam para a modificação do processo e da construção dos programas.

A intenção que permeou - e permeia - o projeto foi de que o aluno se reconhecesse como um sujeito autônomo, capaz de produzir e, também, receber criticamente os produtos do 
campo da comunicação. O projeto de extensão em educomunicação e saúde possibilitou que o aluno se posicionasse nessa perspectiva perante os produtos comunicacionais. Permitiu, também, que a equipe docente promovesse uma troca multidisciplinar entre áreas que, tradicionalmente, pouco se conversam na academia, gerando novas perspectivas de atuação e conhecimento. Nessa direção, os indicadores iniciais apontam como positiva a possibilidade de estabelecer uma competência já na graduação para atender às demandas sociais da comunicação pública de saúde.

\section{REFERÊNCIAS}

BUENO, Wilson da Costa. A cobertura de saúde na mídia brasileira: os sintomas de uma doença anunciada. In: EPSTEIN, Isaac et al. (Orgs.). Mídia e saúde. Adamantina: Unesco/Umesp/FAI, 2001.

COSTA, Maria Cristina Castilho Costa. Educomunicador é preciso. Disponível em: < http://www.usp.br/nce/wcp/arq/ textos/7.pdf>. Acesso em: 30/03/2008.

MARTÍN-BARBERO, Jesús. Dos meios às mediações: comunicação, cultura e hegemonia. Rio de Janeiro: UFRJ, 2003.

MINISTÉRIO DA EDUCAÇÃO. Manual de educomunicação. 2006. Disponível em: < http://www.cdcc.sc.usp.br/ CESCAR/Atualizacao/10.pdf> . Acesso em: 18/02/2008.

PEREIRA JÚNIOR, Ademir. Comunicação em saúde pública: uma análise sobre alguns casos bem sucedidos. In: EPSTEIN, Isaac et al. (Orgs.). Mídia e saúde. Adamantina: Unesco/Umesp/FAI, 2001.
XAVIER, Caco. Mídia e saúde, saúde na mídia. In: SANTOS, Adriana (Org.). Caderno mídia e saúde pública. Belo Horizonte: Escola de Saúde Pública/Funed, 2006. p. 43-56. Disponível em: <http://www.projetoradix. com.br/arq_artigo/livros/midiasaude.pdf $>$. Acesso em: 26/03/2009.

; GORGULHO, M. Dependência: compreensão e assistência às toxicomanias (uma experiência do PROAD). São Paulo: Casa do Psicólogo, 1996. 258 p.

STACECHEN, L. F; BENTO, V. E. S. Consumo excessivo $e$ adicção na pós-modernidade: uma interpretação psicanalítica. Fractal: Revista de Psicologia, Rio de Janeiro, v. 20, n. 2, p. 421-436, jul.-dez. 2008.

Texto recebido em 20 de agosto de 2009. Texto aprovado em 21 de janeiro de 2010 . 